\title{
Precocious puberty: diagnosis and management
}

\author{
Sultana $\mathrm{N}^{\mathrm{a}}$, Afsana $\mathrm{F}^{\mathrm{b}}$, Akhter $\mathrm{N}^{\mathrm{c}}$, Akhter $\mathrm{Y}^{\mathrm{d}}$, Amin $\mathbf{M} \mathrm{F}^{\mathrm{e}}$, Chowdhury $\mathrm{S}^{\mathrm{f}}$, Emran \\ MS $^{g}$, Hasan ABMK ${ }^{h}$, Hossain $\mathrm{T}^{\mathrm{i}}$, Khan MA', Khan $\mathbf{S}^{\mathrm{k}}$, MahbubMI', Mir $\mathrm{AS}^{\mathrm{m}}$, \\ Mustari $\mathbf{M}^{\mathrm{n}}$, Rafiquddin $\mathbf{M}^{\circ}$, Rahman $\mathbf{M A}^{\mathrm{p}}$, Shefin $\mathbf{S} \mathbf{M}^{\mathrm{q}}$, Sultana $\mathrm{D}^{\mathrm{r}}$, Talukder $\mathbf{S} K^{\mathbf{s}}$, \\ Tuqan $\mathbf{S}^{\mathbf{t}}$
}

\begin{abstract}
Precocious puberty is commonly defined as puberty that starts before age 8 years in girls and 9 years in boys. The causes of it may range from a variant of normal development to various pathologic conditions. The etiology of precocious puberty is classified by the underlying pathogenesis into gonadotropin dependent central precocious puberty and peripheral precocious puberty which is independent of gonadotropin but due to different other causes. Variants of precocious puberty include premature thelarche, premature puberche and isolated premature menarche which imply onset of isolated changes without any other signs of sexual development. Precocious puberty might have an impact on final stature owing to premature epiphyseal fusion and also it has got influence on psychosocial wellbeing. Evaluation includes a detailed history, physical examination, biochemical testing and imaging directed towards suspected etiology. Gonadotropin releasing hormone (GnRH) analogues are effective for treatment of central precocious puberty. Treatment of peripheral precocious puberty should be based on the specific cause. Pubertal variants are usually non-progressive and need no treatment but should be monitored carefully.
\end{abstract}

Key words: Precocious puberty, central precocious puberty, peripheral precocious puberty, pubertal variants.

(BIRDEM Med J 2022; 12(1: 62-69)

\footnotetext{
Author information

a. Nusrat Sultana, Assistant Professor, Department of Endocrinology, BSMMU.

b. Faria Afsana, Assistant Professor, Department of Endocrinology, BIRDEM.

c. Nazma Akhtar, Assistant Professor, Department of Endocrinology, Shaheed Tazuddin Ahmed Medical College.

d. Yasmin Aktar, Assistant Professor, Department of Endocrinology, Bangladesh Medical College and Hospital.

e. Mohammad Feroz Amin, Associate Professor, Department of Endocrinology, BIRDEM.

f. Sharmin Chowdhury, Medical Officer, National Institute of Neurosciences and Hospital.

g. Shah Md. Emran, Associate Professor, Department of Endocrinology, Sylhet M.A.G Osmani Medical College and Hospital.

h. ABM Kamrul Hasan, Assistant Prof and Head, Department of Endocrinology, Mymensingh Medical College and Hospital.

i. Tanjina Hossain, Associate Professor, Department of Endocrinology and Metabolism, Green Life Medical college and Hospital.

j. Murshed Ahmed Khan, Assistant Professor, Department of Endocrinology, BSMMU.

k. Shahjamal Khan, Professor \& Head, Department of Endocrinology, Enam Medical College and Hospital.

1. Mohammad Imtiaj Mahbub, Assistant Professor, Sheikh Hasina National Institute of Burn and plastic Surgery.

m. Ahmed Salam Mir, Associate Professor, Department of Endocrinology, BIHS.

n. Marufa Mustari, Endocrinologist, Department of Endocrinology, BSMMU.

o. Md. Rafiquddin, Assistant Professor, Department of Endocrinology, Chittagong Medical college and Hospital.

p. Md. Atikur Rahman, Junior Consultant (in situ) Surgeon Office, Munshiganj.

q. Sultana Marufa Shefin, Assistant Professor, Department of Endocrinology, BIRDEM.

r. Dahlia Sultana, Assistant Professor, Department of Endocrinology, SSMC \&MH.

s. Samir Kumar Talukder, Associate Professor and Head, Department of Endocrinology, Rangpur Medical College and Hospital.

t. Sadiqa Tuqan, Associate Consultant, Square Hospital Ltd.

Address of correspondence: FariaAfsana, Assistant Professor, Department of Endocrinology, BIRDEM General Hospital. Email: fariaafsana@yahoo.com

Received: March 6, 2021

Revision received: September 29, 2021

Accepted: October 31, 2021
} 


\section{INTRODUCTION}

Puberty is the process of maturation that occurs during adolescence and includes acquisition of secondary sexual characteristics, rapid bone maturation, and acceleration of growth. ${ }^{1}$ The term puberty is characteristically used to refer to the physical and endocrine changes of this period, while adolescence usually refers to the profound psychologic changes encountered during this time. ${ }^{2}$ Precocious puberty is commonly defined as puberty that starts before age 8 years in girls and 9 years in boys ${ }^{3}$. The overall incidence of sexual precocity is estimated to be 1:5000 to 1:10,000 with a female to male ratio of $10: 1 .{ }^{4}$ Observational data from the US show that at age 7 years, $10 \%$ of white girls and $23 \%$ of black girls have entered puberty. In Europe, approximately $5 \%$ of girls are thought to have begun breast development before age 8.5 years. ${ }^{1}$ Registry based Danish study using ICD-10 diagnosed estimated prevalence of precocious puberty $0.2 \%$ for girls and $<0.05 \%$ of boys. ${ }^{5}$ The age of puberty is influenced by several factors like genetics, overall health, social environment and environmental exposures. ${ }^{6}$ Normal puberty refers to the time in which $95 \%$ children attain initial pubertal signs. In the 1960s, cross-sectional data led to designation of the normal age range of pubertal onset between ages 8 and 13 years for girls and between ages 9 and 14 years in boys. ${ }^{7,8}$ Many cases of precocious puberty in girls over 6 years have benign causes, but it can indicate serious pathology in some cases. Precocious puberty in boys represents a substantial risk of underlying pathology and requires urgent referral to a pediatric endocrinologist ${ }^{1}$. This review article intended to discuss diagnostic evaluation and treatment plan for boys and girls with precocious puberty.

\section{PHYSIOLOGY OF NORMAL PUBERTY}

Puberty is considered as one stage in the continuing process of growth and development that begins during gestation and con-tinues until the end of reproductive life. ${ }^{8}$ The hypothalamo pituitary gonadal axis (HPG) axis develops and differentiates during fetal life with peak gonadotropin levels achieved at 24 weeks of gestation following which there is a steady decline till birth. After birth, the HPG axis escapes the suppressive effects of maternal and placental hormones that results in pulsatile secretion of gonadotropin releasing hormone ( $\mathrm{GnRH})$ which leads to increasing levels of gonadotropins and sex steroids. At around 3-6 months in boys and 12-18 months in girls the high sensitivity of hypothalamus leads to negative feedback by the low circulating levels of gonadal steroids. Along with central inhibitory mechanisms, this suppresses the gonadotropins to prepubertal levels by 6-9 months in boys and 24-36 months in girls. ${ }^{2,6,8}$ After an interval of child-hood quiescence - the juvenile pause - the hypothalamic pulse generator increases activity in the peripubertal period, just before the physical changes of puberty commence. This leads to increased secretion of pituitary gonadotropins and, subsequently, gonadal sex steroids that bring about secondary sexual development, the pubertal growth spurt, and fertility. This is known as gonadarche ${ }^{8,9}$. Adrenarche is the increase in production of androgens by the adrenal cortex ${ }^{8}$. While puberty encompasses changes due to both gonadarche and adrenarche, the term "puberty" is often used to refer specifically to gonadarche. ${ }^{2}$

\section{CLINICAL ASPECTS OF NORMAL PUBERTY}

During puberty, sexual development occurs as a sequential changes and it varies from person to person. The chart- 1 shows a typical sequence and normal range of development for the milestones of sexual development for girls and boys. ${ }^{10}$ The stages of pubertal change has been described by Marshall and Tanner which is denoted as Sexual Maturation stages (SMR) or, often called Tanner stages. It consists of a series of events that usually proceed in a predictable manner with some variations in timing of onset, sequence, and tempo. SMR (Tanner stages) for pubic hair, breast, and male genitalia consists of five categories, with stage 1 representing pre-puberty and stage 5 representing adult development (Table-I). ${ }^{11,12}$ In most of the girls, the earliest secondary sexual characteristic is breast/areolar development (thelarche), although about 15 percent have pubic hair as the initial manifestation. Menarche occurs, on average, 2.6 years after the onset of puberty and 0.5 years after peak height velocity. In boys, the earliest stage of maturation is almost always an increase in testicular volume, followed by penile growth and the appearance of pubic hair. The appearance of sperm in the urine and the onset of nocturnal sperm emissions occur shortly after the attainment of peak height velocity; many consider these events the male equivalent of menarche. ${ }^{2}$ 

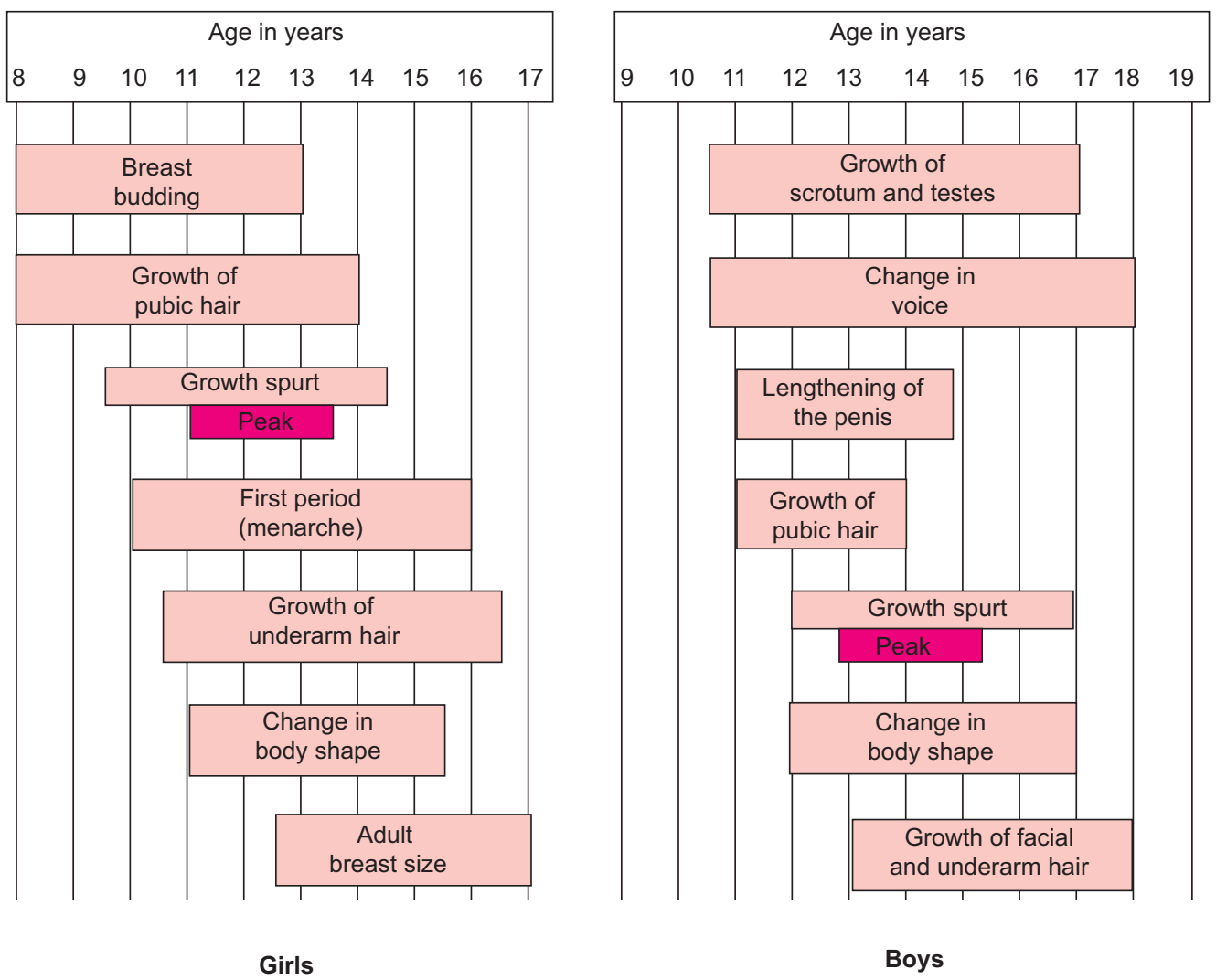

Chart-1 Mile stone of pubertal development in boys and girls

Source: MSD Manual. Early puberty, Sep 2020

Table I Sexual maturity staging (Tanner stages) of secondary sexual characteristics

Boys-Development of external genitalia

Stage-1 Pre-pubertal

Stage-2 Enlargement of testes and scrotum; scrotal skin reddens and changes in texture

Stage-3 Enlargement of penis (length at first); further growth of testes

Stage-4 Increased size of penis with growth in breadth and development of glans; testes and scrotum larger, scrotal skin darker

Stage-5 Adult genitalia

\section{Girls-Breast development}

Stage-1 Pre-pubertal

Stage-2 Breast bud stage with elevation of breast and papilla; areolar enlargement

Stage-3 Further enlargement of breast and areola; no separation of their contour

Stage-4 Areola and papilla for a secondary mound above the level of breast

Stage-5 Mature stage; projection of papilla only, related to recession of areola

\section{Boys and girls-pubic hair}

\section{Stage-1 Pre-pubertal}

Stage-2 Sparse growth of long, slightly pigmented hair, straight or curled, at the base of penis or along labia

Stage-3 Darker, coarser and more curled hair, spreading sparsely over junction of pubes

Stage-4 Hair adult in type but covering small area than in adult; no spread to medial surface of thighs

Stage-5 Adult in type and quantity, with horizontal upper border 


\section{CLASSIFICATION AND ETIOLOGY OF PRECOCIOUS PUBERTY}

The etiology of precocious puberty is classified by the underlying pathogenesis into three categories (algorithm-1). Central precocious puberty (CPP) or true precocious puberty is caused by an early activation of the HPG axis. Although CPP is idiopathic in up to 90 percent of girls and 60 percent of boys, some cases are caused by lesions of the CNS including optic glioma associated with neurofibromatosis type 1, hypothalamic hamartomas, astrocytomas, ependymomas, pinealomashydrocephalus, cysts, trauma, CNS inflammatory disease, and congenital midline defects, such as optic nerve hypoplasia. Children who have been exposed to high serum levels of sex steroid (eg, those with McCune-Albright syndrome and poorly controlled congenital adrenal hyperplasia) may sometimes develop superimposed CPP. True precocious puberty due to gain of function mutations in KISS1R/GRP54 gene in KISS1 gene is also observed. ${ }^{2}$ Finally pituitary gonadotropinsecreting tumors which are extremely rare in children and are associated with elevated levels of LH and/or FSH. ${ }^{13,14}$ Peripheral precocious puberty (PPP) is caused by secretion of sex hormones either from the gonads or adrenal glands, ectopic human chorionic gonadotropin (hCG) production by a germ-cell tumor, or by exogenous sources of sex steroids and is independent from the HPG axis. A functioning follicular cyst of the ovaries is the most common cause of peripheral precocity in girls. ${ }^{15}$ Other causes include estrogen secreting ovarian or adrenal tumor. In boys the causes include leydig cell tumor, hcg secreting germ tumor, virilizing adrenal neoplasm, familial testotoxicosis. ${ }^{16}$ In both boys and girls, McCune-Albright syndrome, hypothyroidism, iatrogenic or exogenous sexual precocity (including inadvertent exposure to estrogens in food, drugs, or cosmetics) are responsible for sexual precocity. ${ }^{2,17}$ PPP can be contra-sexual whereupon feminization in boys due to adrenal neoplasm, late-onset adrenal hyperplasia and virilization in girls due to congenital adrenal hyperplasia, virilizing adrenal, or ovarian neoplasm occur. $^{2}$

Benign pubertal variants include isolated breast development (premature thelarche), isolated pubic hair development (premature pubarche/adrenarche), benign pre pubertal vaginal bleeding, and non-progressive precocious puberty. These patterns are usually a variant of normal puberty and require no intervention. ${ }^{9}$

Algorythm 1 Classicication of precocious puberty

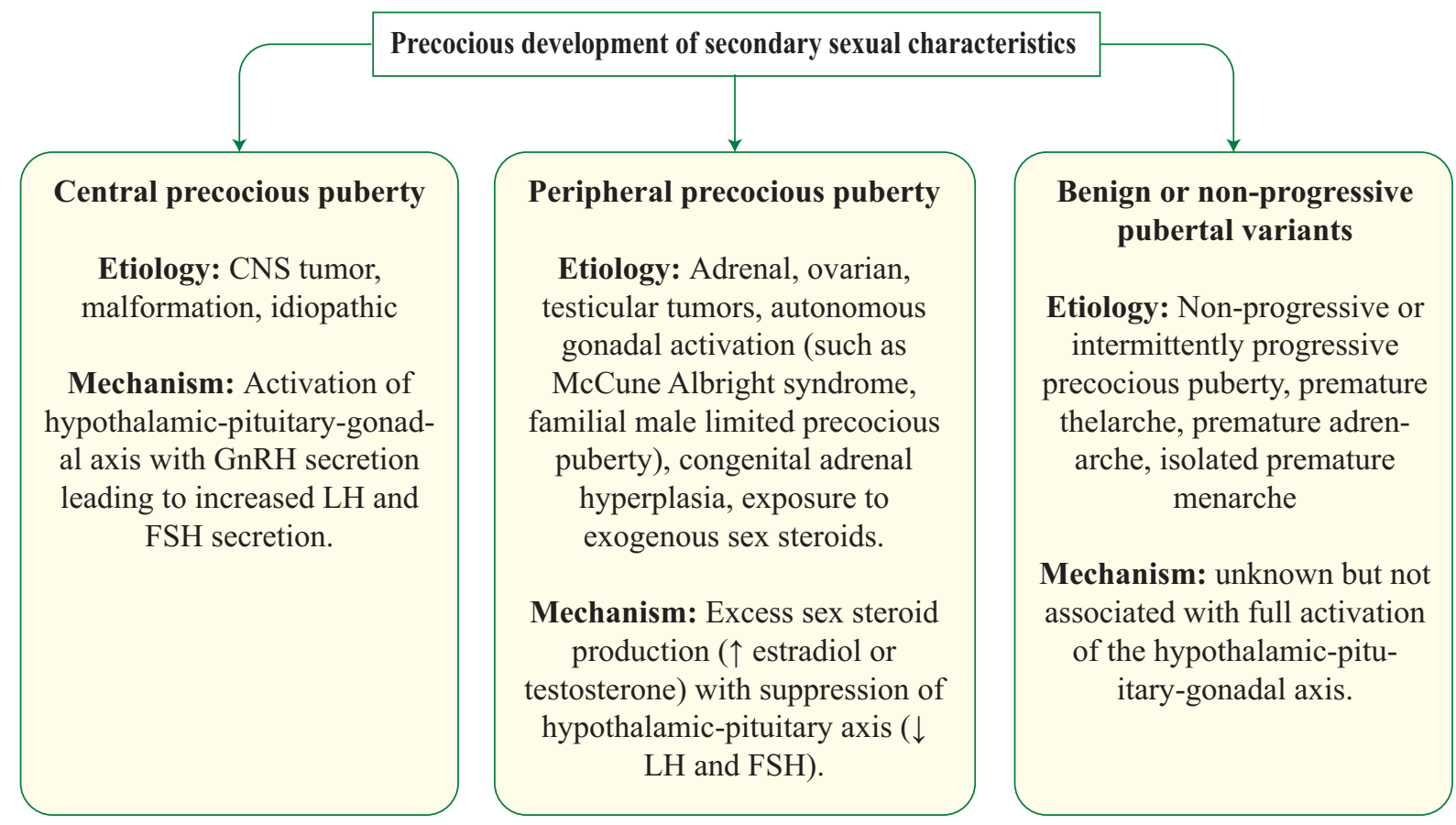




\section{CAUSES OF PRECOCIOUS PUBERTY AND BANGLADESH PERSPECTIVE}

In an observational study in Bangladesh including 71 patients presented with precocious puberty during the period from 2005 to 2015, it was found that precocious puberty was more common among girls as compared to boys. Mean age at presentation of girls and boys were $4.8 \pm 2.1$ years and $6.63 \pm 1.4$ years respectively. Among girls who presented with precocious puberty, $43.1 \%$ had CPP and of them $86.3 \%$ were idiopathic in origin. 9.8\% of girls had PPP and the causes were congenital adrenal hyperplasia (CAH) $60 \% \& 40 \%$ had adrenal adenoma.

On the other hand boys mostly suffered from PPP and $\mathrm{CAH}$ was the commonest cause. Other causes were adrenal adenoma (18.1\%) and hepatoblastoma (9\%). Among boys, $35 \%$ had CPP and the causes were hypothalamic hamartoma ( $42.8 \%$ ), craniopharyngioma (14.2\%) and $42.8 \%$ boys had idiopathic CPP. Among cases of puberty variants, $83.3 \%$ had premature thelarche, $4.1 \%$ had premature menarche $\& 12.5 \%$ had premature adrenarche. ${ }^{18}$

\section{DIAGNOSIS OF PRECOCIOUS PUBERTY}

Diagnostic approach of precocious puberty starts with demonstration of progressive signs of secondary sexual characteristics in boys and girls who are younger than the age of normal pubertal development in respect to their age and sex. The next concern is to classify the types of sexual precocity and subsequently to determine the causes behind it. Initial evaluation begins with a history and physical examination which focus on when the pubertal changes were first noted, as well as the timing of pubertal onset in the parents and siblings. In most cases, radiographic measurement of bone age is performed to determine whether there is a corresponding increase in epiphyseal maturation which is a concern for predicting final adult height. ${ }^{2,6}$ The pace of pubertal development reflects whether the cause is CPP or PPP or it can suggest a benign pubertal variant. A rapid rate of linear growth and skeletal maturation (measured as advanced bone age) suggests either CPP or peripheral precocity. By contrast, a child with normal linear growth and skeletal maturation (bone age normal or minimally advanced) suggests a benign pubertal variant. ${ }^{19,20}$ In CPP the sequence of pubertal development displays normal pubertal development but at an earlier age which maintains sequence of changes of normal puberty. By contrast, individuals with peripheral precocity have a peripheral source of gonadal hormones and are more likely to show deviations from the normal sequence and/ or pace of puberty. Additional histories are directed toward evidence of a particular disease entity include, headaches, changes in behavior or vision, seizures, or abdominal pain and previous history of CNS disease or trauma. The possibility of exposure to exogenous sex steroids (medicinal or cosmetic sources) or compounds with sex steroid-like properties (endocrine-disrupting chemicals, for example) should always be explored. Another point to be looked for is that if the secondary sexual characteristics are virilizing or feminizing. Isolated contrasexual development (isolated virilization in girls or isolated feminization in boys) excludes central etiologies.

Physical examination includes measurement of height, weight, and height velocity ( $\mathrm{cm} /$ year) and assessment of pubertal stages by Tanner staging. ${ }^{13,14}$ Boys suspected to be having CPP would generally have symmetrically enlarged testicular volumes, while with PPP testes are typically prepubertal, or having asymmetrical enlargement or extremely small compared to the amount of virilizing signs these children demonstrate. ${ }^{6}$ Children with benign forms of precocious puberty do not usually display the early growth acceleration pattern that is seen among those with progressive forms of precocious puberty. ${ }^{21}$

A good initial screening test to identify activation of the HPG axis is measurement of basal serum LH concentration (ideally in the morning), using sensitive immunochemiluminescence assays with a lower limit of detection of $\leq 0.1 \mathrm{mIU} / \mathrm{mL}$. The other tests are serum FSH, and either estradiol and/or testosterone concentrations. The results are used to differentiate between CPP and peripheral precocity, which then guides additional testing. ${ }^{22}$ The gold standard for diagnosis of CPP is gonadotropin releasing hormone $(\mathrm{GnRH})$ stimulation test where the LH levels are measured 15-60 min after GnRH stimulation/GnRH analogue administration. A prepubertal LH pulse reaches 1.5-2.0 U/L whereas a level greater than 4-5 U/L suggests that puberty has begun. Unstimulated prepubertal levels of LH is usually less than $0.1 \mathrm{U} / \mathrm{L}^{6}$. In boys, human chorionic gonadotropin ( $\mathrm{hCG}$ ) should be measured to evaluate for the possibility of an hCG-secreting tumor leading to peripheral precocity. If a tumor is found in the 
anterior mediastinum, a karyotype should be performed to evaluate for Klinefelter syndrome because of its association with mediastinal germinoma. ${ }^{23}$ A thyroidstimulating hormone (TSH) concentration should be measured if chronic primary hypothyroidism is suspected as the underlying cause for the sexual precocity. Other hormonal tests include adrenal steroidsdehydro epiandrosterone sulphate (DHEA-S), $17 \mathrm{OH}$ progesterone, androstenedione which are raised in adrenal tumors, congenital adrenal hyperplasia (CAH) and ACTH stimulation tests to diagnose $\mathrm{CAH}^{6}{ }^{6}$

Contrast-enhanced brain magnetic resonance imaging (MRI) is recommended for all boys with CPP and for girls with onset of secondary sexual characteristics before 6 years of age because of higher rates of CNS abnormalities in these groups of patients. ${ }^{24}$ Other imaging studies include pelvic ultrasound to assess of uterine size, shape and endometrial echo which reflect the effect of estrogen, ovarian volumes and size/number of follicles identified reflect gonadotropin effect. In children where an adrenal tumor is suspected (due to evidence of progressive virilization and elevated serum adrenal androgens, eg, DHEAS), an abdominal ultrasound and/or computed tomography (CT) of the abdomen should be performed. ${ }^{2,6}$ In boys with suspected PPP, USG of testes is done to find out testicular abnormality. 2,5

\section{MANAGEMENT OF PRECOCIOUS PUBERTY}

The objectives of treatment for children with precocious puberty are to try to attain normal adult height, address psychosocial problems caused by early pubertal development and to detect and treat any correctable cause if present.

\section{TREATMENT FOR CENTRAL PRECOCIOUS PUBERTY}

Pubertal progression in CPP can be arrested by administration of GnRH agonist. This treatment can be used for patients with idiopathic or neurogenic CPP. ${ }^{25,26}$ or for secondary activation of CPP. When CPP is caused by an identifiable central nervous system (CNS) lesion, therapy is also directed towards the underlying pathology when possible. ${ }^{27}$ The decision of whether to treat CPP with a GnRH agonist depends upon the child's age, the rate of pubertal progression, height velocity, and the estimated adult height as determined from the rate of bone age advancement. ${ }^{28} \mathrm{GnRH}$ agonist therapy for a girl is suggested when presenting with progressive pubertal change before the age of 6 years with breast and pubic hair development, advanced bone age, and accelerated height velocity. Conversely, in a girl with somewhat later onset of CPP and/or historically slow progression of pubertal development without a substantial increase in height velocity, monitoring without treatment for three to six months without making treatment decision is suggested. ${ }^{29,30}$ For boys, treatment with GnRH agonist is suggested for those presenting with CPP before the age of nine years, unless there is evidence of slow pubertal progression. ${ }^{31}$ Sustainedrelease formulations of several $\mathrm{GnRH}$ agonists have been developed: depot preparations for monthly, three, or six-monthly dosing and a subcutaneous implant that is surgically inserted every 12 months. ${ }^{26}$ The choice of GnRH agonist formulation depends on patient and clinician preference and local regulatory approvals. ${ }^{30}$ After GnRH agonist therapy has begun, ongoing careful clinical assessment is paramount and follow-up monitoring should be performed. Effective GnRH agonist therapy should result in a decrease in height velocity, cessation of menses, and arrest pubertal progression. Periodic bone age measurements are done looking for a reduction in the bone age advancement at every six to twelve months. ${ }^{25,29}$ If there is evidence of ongoing pubertal progression once therapy has begun, then measurement of LH and sex steroids may be used to assess whether there is complete suppression of the pituitary-gonadal axis. ${ }^{32,33}$ If this testing shows incomplete suppression of the pituitary-gonadal axis, the GnRH agonist dose should be increased or the interval between doses decreased. The decision to stop treatment is based on the age of puberty of peers, siblings and parents and wishes of the patient and family. Discontinuation of treatment at chronological age 11 years (bone age 12) has been associated with maximal adult height. ${ }^{34}$ Therapy after 11 to 12 years of age carries the theoretical risk of preventing normal calcium accretion by the skeleton; therefore not recommended to continue treatment beyond this age. ${ }^{35}$ Treatment with GnRH agonists appears to have no significant longterm effects on the pituitary-gonadal axis. ${ }^{36}$

\section{TREATMENT FOR PERIPHERAL PRECOCITY}

PPP due to tumors of the testis, adrenal gland, or ovary are treated by surgery. HCG-secreting tumors may additionally require radiation therapy and chemotherapy, 
depending upon the site and histologic type. Functioning follicular cysts of the ovary usually regress spontaneously, so conservative management without surgery is generally appropriate. ${ }^{37-39}$ Patients should be followed clinically to document regression in the clinical signs of precocity. If there is no clinical evidence of pubertal regression, ultrasonography of the ovaries should be performed. Exposure to exogenous sex steroids - the source should be identified and removed. After removal, the pubertal changes are likely to regress.

Defects in adrenal steroidogenesis, such as classic $\mathrm{CAH}$ should be treated with glucocorticoids. McCuneAlbright syndrome (MAS) and familial male-limited precocious puberty are disorders that require a different approach because they are caused by mutations resulting in overstimulation of the tissues that produce sex steroids. Treatment with letrozole has become one of the commonly used therapeutic approaches for girls with MAS. ${ }^{40}$

\section{BENIGN OR NON-PROGRESSIVE PUBERTAL VARIANTS}

These condition are benign, non-progressive, selflimited disorders and usually only reassurance and follow-up are necessary. Clinical follow-up is essential because some patients with an initial presentation that is consistent with a benign pubertal variant will turn out to have a progressive disorder such as central precocious puberty (CPP) or peripheral precocity. If reexamination confirms lack of rapid progression in secondary sexual characteristics, these children need no therapy. ${ }^{2,8}$

\section{Conclusion}

Appropriate management of precocious puberty demands correct diagnosis and timely intervention. Though CPP in many cases are idiopathic but treatment is needed to halt its progression for the concern of final stature and to avoid psychosocial problems. PPP should be addressed with care to eliminate potential correctable causes. At the same time benign non-progressive pubertal variants need to be monitored closely to demonstrate its benign nature. Precocious puberty is always a source great worry for the parents of the affected children. Therefore, proper counselling is equally important as important is medical or surgical management.
Authors' contribution: NS drafted the manuscript FA reviewed, All authors red, reviewed and approved the final manuscript.NS drafed the manscript FA reviewed, All authors red, reviwed and approved the final anscript.

Conflicts o interset: Nothing to declare

\section{REFERENCES}

1. Bradley SH, Lawrence N, Steele C, Mohamed Z. Precocious puberty. BMJ 2020; 368:16597.

2. Melmed S, Auchus RJ, Goldfine AB, Koenig RJ, Rosen CJ. Williams Textbook of Endocrinology. $14^{\text {th }}$ ed. Philadelphia: Elsevier; 2020. 26: Physiology of Growth and Puberty; p.1283-1422.

3. Muir A. Precocious puberty. Pediatr Rev 2006;27:37381.

4. Tirumuru SS, Arya P, Latthe P. Understanding precocious puberty in girls. Obstetrician Gynaecologist 2012;14:121-9.

5. Teilmann G, Pedersen CB, Jensen TK, Skakkebaek NE, Juul A. Prevalence and incidence of precocious pubertal development in Denmark: an epidemiologic study based on national registries. Pediatrics 2005;116:1323-8.

6. Pallavi P, Samal R. Precocious puberty: a clinical review. Int J Reprod Contracept Obstet Gynecol 2018; 7(3):771-7.

7. Latronico AC, Brito VN, Carel JC. Causes, diagnosis, and treatment of central precocious puberty. Lancet Diabetes Endocrinol 2016;4:265-74.

8. Gardner DG and Shoback D. Greenspan's Basic \& Clinical Endocrinology. 10 ${ }^{\text {th }}$ ed. USA: Mac Graw Hill Education; 2018. 15: Puberty; p.547-575.

9. Biro FM, Galvez MP, Greenspan LC, Succop PA, Vangeerpuram N, Pinney SM, et al. Pubertal assessment method and baseline characteristics in a mixed longitudinal study of girls. Pediatrics 2010;126:e583-90.

10. MSD Manual. Early puberty, Sep 2020.

11. Marshall WA, Tanner JM. Variations in Pattern of pubertal changes in girls. Arch Dis Child 1969; 44: 291.

12. Marshall WA, Tanner JM. Variations in Pattern of pubertal changes in boys. Arch Dis Child 1970; 45:13.

13. Faggiano M, Criscuolo T, Perrone L, Quarto C, Sinisi AA. Sexual precocity in a boy due to hypersecretion of $\mathrm{LH}$ and prolactin by a pituitary adenoma. Acta Endocrinol (Copenh) 1983; 102:167.

14. Ambrosi B, Bassetti M, Ferrario R. Precocious puberty in a boy with a PRL-, LH- and FSH-secreting pituitary tumour: hormonal and immunocytochemical studies. Acta Endocrinol (Copenh) 1990; 122:569.

15. Atay Z, Yesilkaya E, Erdeve SS, Turan S, Akin L, Eren E, et al. The Etiology and Clinical Features of Non-CAH Gonadotropin-Independent Precocious Puberty: A Multicenter Study. J Clin Endocrinol Metab 2016; 101:1980. 
16. Shenker A, Laue L, Kosugi S, Merendino JJ, Minegishi T, Cutler GB. A constitutively activating mutation of the luteinizing hormone receptor in familial male precocious puberty. Nature 1993; 365:652.

17. Nabhan ZM, West KW, Eugster EA. Oophorectomy in McCune-Albright syndrome: a case of mistaken identity. J Pediatr Surg 2007; 42:1578.

18. Ahmed T, Mohsin F, Islam N, Nahar J, Akhter S, Azad K. Aetiology of Precocious Puberty in Patients presenting to a Tertiary Care Hospital. Bangladesh J Child Health 2017; 41 (3): 143-6.

19. Heller ME, Dewhurst J, Grant DB. Premature menarche without other evidence of precocious puberty. Arch Dis Child 1979; 54:472.

20. Hill NC, Oppenheimer LW, Morton KE. The aetiology of vaginal bleeding in children. A 20 -year review. Br J Obstet Gynaecol 1989; 96:467.

21. Papadimitriou A, Beri D, Tsialla A, Fretzayas A, Psychou F, Nicolaidou P. Early growth acceleration in girls with idiopathic precocious puberty. J Pediatr 2006; 149:43.

22. Neely EK, Hintz RL, Wilson DM, Gautier T, Argente J, Stene M. Normal ranges for immuno-chemiluminometric gonadotropin assays. J Pediatr 1995; 127:40.

23. Englund AT, Geffner ME, Nagel RA, Lippe BM, Braunstein GD. Pediatric germ cell and human chorionic gonadotropin-producing tumors. Clinical and laboratory features. Am J Dis Child 1991; 145:1294.

24. Mogensen SS, Aksglaede L, Mouritsen A, Sorensen K, Main KM, Gideon P, et al. Pathological and incidental findings on brain MRI in a single-center study of 229 consecutive girls with early or precocious puberty. PLoS One 2012; 7:e29829.

25. Boepple PA, Mansfield MJ, Wierman ME, Rudlin CR, Bode HH, Crigler JF, et al. Use of a potent, long acting agonist of gonadotropin-releasing hormone in the treatment of precocious puberty. Endocr Rev 1986; 7:24.

26. Crowley WF Jr, Comite F, Vale W, Rivier J, Loriaux DL, Cutler Jr GB. Therapeutic use of pituitary desensitization with a long-acting lhrh agonist: a potential new treatment for idiopathic precocious puberty. J Clin Endocrinol Metab 1981; 52:370.

27. Mahachoklertwattana P, Kaplan SL, Grumbach MM. The luteinizing hormone-releasing hormone-secreting hypothalamic hamartoma is a congenital malformation: natural history. J Clin Endocrinol Metab 1993; 77:118

28. Carel JC, Léger J. Clinical practice. Precocious puberty. N Engl J Med 2008; 358:2366.
29. Carel JC, Eugster EA, Rogol A, Ghizzoni L, Palmert MR. Consensus statement on the use of gonadotropin-releasing hormone analogs in children. Pediatrics 2009; 123:e752.

30. Bangalore Krishna K, Fuqua JS, Rogol AD, Klein KO, Popovic J, Houk CP, et al. Use of Gonadotropin-Releasing Hormone Analogs in Children: Update by an International Consortium. Horm Res Paediatr 2019; 91:357.

31. Lazar L, Pertzelan A, Weintrob N, Phillip M, Kauli R. Sexual precocity in boys: accelerated versus slowly progressive puberty gonadotropin-suppressive therapy and final height. J Clin Endocrinol Metab 2001; 86:4127

32. Bhatia S, Neely EK, Wilson DM. Serum luteinizing hormone rises within minutes after depot leuprolide injection: implications for monitoring therapy. Pediatrics 2002; 109:E30.

33. Demirbilek H, Alikasifoglu A, Gonc NE, ozon A, Kandemir N. Assessment of gonadotrophin suppression in girls treated with GnRH analogue for central precocious puberty; validity of single luteinizing hormone measurement after leuprolide acetate injection. Clin Endocrinol (Oxf) 2012; $76: 126$.

34. Lazar L, Padoa A, Phillip M. Growth pattern and final height after cessation of gonadotropin-suppressive therapy in girls with central sexual precocity. J Clin Endocrinol Metab 2007; 92(9): 3483-9.

35. Raine JE, Donaldson MDC, Gregory JW, Vliet GV. Practical Endocrinology and Diabetes in Children. $3^{\text {rd }}$ ed. UK: Wiley-Blackwell; 2011. 5: Puberty; p.91-115.

36. Thornton P, Silverman LA, Geffner ME, Neely EK, Goulg E, Danoff TM. Review of outcomes after cessation of gonadotropin-releasing hormone agonist treatment of girls with precocious puberty. Pediatr Endocrinol Rev 2014; 11:306.

37. Lee PA, Kerrigan JR. Precocious Puberty. In: Pediatric Endocrinology, Pescovitz OH, Eugstr EA (Eds), Lippincott Williams and Wilkins, Philadelphia 2004. p.329.

38. Papanikolaou A, Michala L. Autonomous Ovarian Cysts in Prepubertal Girls. How Aggressive Should We Be? A Review of the Literature. J Pediatr Adolesc Gynecol 2015; 28:292.

39. De Sousa G, Wunsch R, Andler W. Precocious pseudopuberty due to autonomous ovarian cysts: a report of ten cases and long-term follow-up. Hormones (Athens) 2008; 7:170.

40. Javaid MK, Boyce A, Appelman-Dijkstra N. Best practice management guidelines for fibrous Gdysplasia/McCuneAlbright syndrome: a consensus statement from the FD/ MAS international consortium. Orphanet J Rare Dis 2019; 14:139. 